\title{
Synthesis and Characterization of Alumina filled Polyesteramide Derived from Jatropha curcas Seed oil
}

\author{
GHAZALA IMRAN, SAGEER AHAMAD and S.A. AHMAD \\ Department of Chemistry, G.F. College, Shahjahanpur - 242001, India \\ http://dx.doi.org/10.13005/ojc/310169
}

(Received: December 02, 2014; Accepted: January 17, 2015)

\begin{abstract}
The Jatropha curcas seed oil converted to N,N-bis (2-hydroxy ethyl) fatty amide (JCHEFA) by reacting with diethanol amine. JCHEFA reacted with phthalic acid to obtained Jatropha curcas polyesteramide (JCPEA). The JCPEA treated with aluminium hydroxide to synthesized alumina filled polyesteramide (JCAPEA). The synthesized JCHEFA, JCPEA and JCAPEA have been characterized by the measurement of physic-chemical properties like specific gravity, refractive index, acid value, iodine value, soponification value. The synthesized intermediates and the final resin were also characterized by FT-IR, ${ }^{1}$ HNMR spectroscopic analyses.
\end{abstract}

Key words: Jatropha curcas, Seed oil, Polyesteramide, Alumina filled polymers.

\section{INTRODUCTION}

Polyesteramide resins are amide modified alkyds which contain both amide (-CONH-) and ester (-COOC-) linkages and known for the improve performances over traditional alkyds ${ }^{1-3}$. Incorporation of aluminium in the polymeric resin further improves the performances notably in terms adhesion, hardness and the water vapor resistance ability ${ }^{4}$.

Use of renewable raw materials in the chemical industries attracted the attention of academia and scientist as it reduces the dependence on non-renewable resources such as petroleum ${ }^{5,6}$. Over the past few decades vegetable oils have served as a viable alternative of the petroleum ${ }^{7,8,9}$. The vegetable oils are triglyceride of different saturated and unsaturated fatty acids has been widely used in making different kind of polymeric resins like alkyd, polyester, epoxy, polyesteramides and many others ${ }^{10-12}$. The oil of different seeds like linseed, castor, soybean, sunflower pongamia glabra, annona sequamosa etc have been largely used in making aforementioned polymeric resins ${ }^{4,11,13,14}$. These polymeric resins are largely used in chemical industries in making paints, coatings, adhesives, binder for composites ${ }^{8,10}$. 
Jatropha curcas is medium sized tree largely cultivated in rural areas. It grows rapidly in hardy to dry weather conditions. Jatropha curcas tree yielded non edible seeds which contain about $48 \%$ oil. The seed oil- a triglyceride which contain appropriate percentage of unsaturated fatty acids ${ }^{15}$.

Keeping these facts in mind and abundant availability of the Jatropha curcas seed oil in present work we have make an effort to utilize this seed oil in making alumina filled polyesteramide.

\section{EXPERIMENTAL}

\section{Materials}

The seeds of Jatropha curcas were collected from the local areas of Shahjahanpur district. The oil was extracted from the dried and crushed seeds through the soxhlet apparatus using petroleum ether as a solvent $\left(60-80^{\circ}\right)$. The fatty acid composition and the results of the physico-chemical characterizations are summarized in the Table 1. Phthallic acid, diethyl ether, methanol were used of analytical grade (Merk-India). Diethanol amine of analytical grade procured from the s.d. Fine chemicals India and was distilled under reduced pressure before use.

\section{Synthesis of Jatropha curcas N,N-bis (2-hydroxy ethyl) fatty amide (JCHEFA)}

Diethanol amine $0.03 \mathrm{~mol}$ was taken in four necked round bottom flask fitted with an electrical stirrer, thermometer, dropping funnel and condenser. The reaction mixture was heated at $180 \pm 5{ }^{\circ} \mathrm{C}$. The Jatropha curcas oil $(0.1 \mathrm{~mol})$ was added drop wise into the reaction mixture over a period of one hour. The progress of the reaction was monitored by TLC. After the completion of the reaction the product was dissolve in diethyl ether and washed with dilute aqueous sodium chloride solution. The ethereal solution filtered and evaporated in rotatory vacuum evaporator to obtained JCHEFA.

\section{Synthesis of Jatropha curcas Polyesteramide} (JCPEA)

JCHEFA and phthalic acid in equal molar ratio and xylene as a solvent were placed in four necked round bottom flask fitted with a Dean-stark trap thermometer and mechanical stirrer. Reaction mixture was heated up to $200 \pm 5^{\circ} \mathrm{C}$. The progress of reaction was monitored by taking the acid value ${ }^{12}$ at regular intervals. After the completion of reaction the product was taken out from the reaction flask and excess of xylene was removed under reduce pressure to obtain JCPEA.

\section{Synthesis of Alumina filled Polyesteramide (JCAEA)}

Polyesteramide of Jatropha curcas seed oil $(0.01$ mole) dissolved in xylene was placed in four necked round bottom flask fitted with Deanstark trap, thermometer and mechanical stirrer. The aluminium hydroxide, $\mathrm{Al}(\mathrm{OH})_{3} 0.004$ mole added to the reaction mixture. The content heated up to the $140{ }^{\circ} \mathrm{C}$. The progress of reaction was monitored by the taking acid values at regular intervals. After completion of reaction the product was taken out from the reaction flask and excess of xylene was removed under reduce pressure to obtain JCAPEA.

\section{Test methods}

Physico chemical characterizations of JCHEFA, JCPEA and JCAPEA were performed as per standard laboratory methods ${ }^{12}$. The structural elucidation was carried out by FT-IR, ${ }^{1}$ HNMR spectroscopic techniques. The FT-IR spectra of these materials were taken on Perkin Elmer 1750 FT-IR spectrometer (Perkin Elmer Citus instruments Norwalk CT) using $\mathrm{NaCl}$ cell. ${ }^{1} \mathrm{HNMR}$ spectra of the resins were recorded on Jeol GSX $300 \mathrm{MHz} F X$ 1000 spectrometer using deuterated chloroform and DMSO as a solvent and tetra methyl silane as an internal standard.

\section{RESULTS AND DISCUSSION}

Figure 1 show the scheme for the preparation of JCHEFA, JCPEA and JCAPEA. Significant increase in the hydroxyl value indicates the conversion of triglyceride (oil) into diol (JCHEFA). The JCHEFA reacted with phthalic acid to obtained polyesteramide through the condensation polymerization. The progressive decrease in acid values indicates the conversion of carboxylic group to ester linkage with reaction of hydroxyl group of JCHEFA. The same was confirmed by the collection of water in Dean-Stark trap. Polyesteramide contain both carboxylic and hydroxyl groups at the terminals. The carboxyl terminal of JCPEA coupled with the 
Table 1: Characterization of JCSO, JCHEFA, JCPEA and JCAPEA

\begin{tabular}{llcccc}
\hline S.No. & Characterization & JCSO & JCHEFA & JCPEA & JCAPEA \\
\hline 1. & Oil Content & 48 & - & - & - \\
2. & Gardener color no. & 4 & 5 & 6 & 5 \\
3. & Specific gravity & 0.927 & 0.938 & 0.948 & 0.988 \\
4. & Refractive index & 1.475 & 1.448 & 1.528 & 1.562 \\
5. & lodine value & 75.18 & 30 & 24 & 12 \\
6. & Acid value & 4.45 & - & 10.6 & - \\
7. & Saponification value & 180 & - & - & 96 \\
8. & Fatty Acid composition & & & & \\
\end{tabular}

$\mathrm{Al}(\mathrm{OH})_{3}$ and produces alumina filled polyesteramide (JCAPEA).

The IR spectrum of JCHEFA shows the strong band at $3440 \mathrm{~cm}^{-1}$ a characteristic band for the primary alcoholic group. In addition to this band carbonyl of amide appears at $1640 \mathrm{~cm}^{-1}$ indicate the formation of amide linkage. The band for the aliphatic chain $\mathrm{CH}_{2}$ appears at $2840-2920 \mathrm{~cm}^{-1}$ for symmetric and asymmetric stretching respectively.
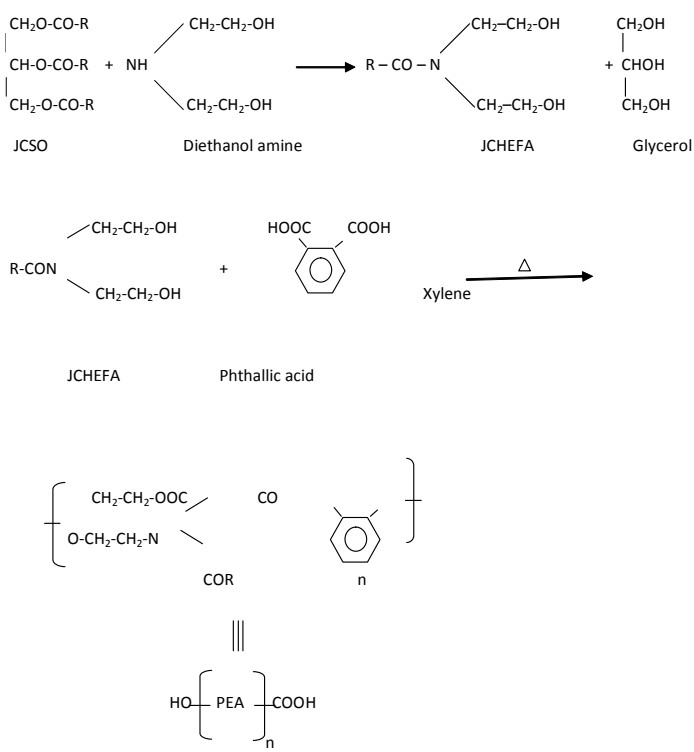

Polyesteramide (JCPEA)

Fig. 1(a): Synthesis of Jatrofa curcus Polyesteramide (JCPEA)
The ${ }^{1}$ HNMR spectrum of JCHEFA shows the peak at $\delta=3.6 \mathrm{ppm}$ for the $\mathrm{CH}_{2}$ attached to the nitrogen of amide, $\mathrm{CH}_{2}$ attached to hydroxyl group appears at $4.4 \mathrm{ppm}$. The multiplet peak for proton of double bonded carbons appears at 5.2-5.6 ppm. In addition to these peaks terminal methyl group appears at $0.90 \mathrm{ppm}$ and aliphatic chain $\mathrm{CH}_{2}$ appears as multiplet at 1.2-1.50 ppm.<smiles>CCC(=O)OC(=[OH+])C(CC)(CC)CC</smiles>
Xylene

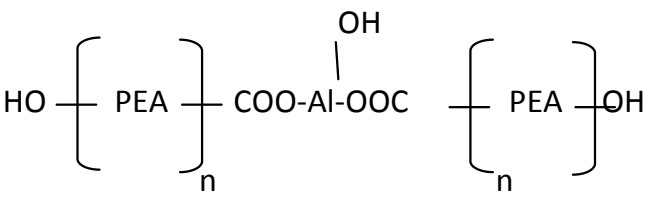

Fig. 1(b): Synthesis of Jatrofa curcus Alumina filled Polyesteramide (JCAPEA) 
The IR spectrum of JCPEA shows band at $1746 \mathrm{~cm}^{-1}$ for the carbonyl of ester in addition to band at $1642 \mathrm{~cm}^{-1}$ of the amide confirm the formation of ester linkage as repeating unit. The other characteristic bands like strong band at $3410 \mathrm{~cm}^{-1}$ appears for alcoholic group, symmetric and asymmetric bands for the chain $\mathrm{CH}_{2}$ appears at 2862 $\mathrm{cm}^{-1}$ and $2940 \mathrm{~cm}^{-1}$ respectively; whereas the characteristic band for the disubstituted benzene ring appears at $770 \mathrm{~cm}^{-1}$.

The ${ }^{1} \mathrm{HNMR}$ spectrum of JCPEA show the sharp peak of chain $-\mathrm{CH}_{2}$ - adjacent to carbonyl of ester at $2.0 \mathrm{ppm}$, multiplet peak for the $-\mathrm{CH}=\mathrm{CH}$ appears at $\delta=5.29-5.36 \mathrm{ppm}$, aromatic proton appears at $\delta=7.28-7.40 \mathrm{ppm}$, broad peak for chain $-\mathrm{CH}_{2}$ - appears at $\delta=1.20-1.30 \mathrm{ppm}$, terminal $-\mathrm{CH}_{3}$ appears at $\delta=0.92 \mathrm{ppm}$.

The IR spectrum of JCAPEA shows the band at $1760 \mathrm{~cm}^{-1}$ for the carbonyl of ester and $1664 \mathrm{~cm}^{-1}$ for carbonyl of amide. The band for $-\mathrm{OH}$ group appears at $3520 \mathrm{~cm}^{-1}$; whereas bands for the $-\mathrm{CH}_{2}$ - symmetric and asymmetric stretching appears at $2866 \mathrm{~cm}^{-1}$ and $2946 \mathrm{~cm}^{-1}$ respectively. It has been found that absorption bands for the carbonyl of ester and amides both shifted mark ably in higher frequency region on incorporation of alumina. Furthermore band for the $-\mathrm{OH}$ group appears in higher frequency region and also more spreads.

The ${ }^{1}$ HNMR spectrum of JCAPEA show the sharp peak of chain $-\mathrm{CH}_{2}$ - adjacent to carbonyl of ester at $2.1 \mathrm{ppm}$, multiplet peak for the $-\mathrm{CH}=\mathrm{CH}$ appears at $\delta=5.31-5.37 \mathrm{ppm}$, aromatic proton appears at $\delta=7.6-8.2 \mathrm{ppm}$, broad peak for chain $\mathrm{CH}_{2}$ - appears at $\delta=1.20-1.32 \mathrm{ppm}$, terminal $-\mathrm{CH}_{3}$ appears at $\delta=0.93 \mathrm{ppm}$. It has been found that peak for the aromatic proton shifted towards down field due the presence of alumina in polymer backbone ${ }^{16}$.

\section{CONCLUSION}

Jatropha curcus seed oil a renewable and abundantly available raw material utilized successfully in the synthesis of Polyesteramide and alumina filled polyesteramie resins. Utilization of renewable resources in chemical industries reduces the pressure on consumption of non renewable resources like petroleum. The synthesized resins were characterized by taking the physical and chemical properties and by spectroscopic studies.

\section{REFERENCES}

1. Hussain, S. Fawcett, A.H. and Taylor, P. Prog. in Org. coat. ,2002, 45,435

2. Ansari, S.H., Imran, G., Naseem, M., Ahmad, S.A. and Hasnat, A. Orient. J. Chem. 2012,28 607

3. Nayak, P., Mishra, D.K., Parida, D., Shahoo, K. C., Nanda, M., Lenka, S. and Nayak, P. L. J. Appl. Polym. Sci. 1997. 63671

4. Ansrai, S.H., Naseem, M., Hasnat, A. and Ahmad S.A. Biosci. Biotech. Res. Asia2011. 8829

5. Kazemi, M. and Dadkhah, A. Orient. J. Chemistry 2012., 28

6. Ahmad, S., Naqvi, F., Verma, K.L., Yadav, S. J. Appl. Polym. Sci. 1999.721679

7. Sharmin, E, Ashraf, S. M., Ahmad S. Eur. J. Lipid Sci. Technol. 2007. 109134
8. Zafar, F., Ashraf S.M., Ahmad S. J. Appl. Polym. Sci. 2007. 10451

9. Zafar, F., Ashraf, S.M., Ahmad, S. Prog. In Org. Coat. 2004. 51250

10. Raval, D. A., Patel, V. M. Paintindia 2005. 351

11. Yeganesh H., Mehdizadeb, H.R., Eur. Polym. J. 2004.,.40 1233

12. Yadav S., Zafar, F., Hasnat A., and Ahmad, S. Prog. in Org. coat. 2009. 6427

13. Sharif Ahmad, Ashraf, S.M., Hasnat A. and Yadav, S. J. Appl. Polym. Sci. 2001.821855

14. Gunduz G. Khalid AH Mecidoglu A. and Aras, L. Prog. in Org. coat. 2004.49259

15. Ambastha, S.P. Useful Plants of India CSIR New Delhi 1986.

16. Silverstein, R.M.Bassler G.C. and Morril T.C. spectroscopic Identification of Organic Compounds, Fifth ed, Wiley, New York, 1991. 